Journal of Social Sciences 8 (3): 318-324, 2012

ISSN 1549-3652

(C) 2012 Science Publications

\title{
Towards Constructivist Teacher Professional Development
}

\author{
Pitsoe, V.J. and W.M. Maila \\ Department of Educational Studies, \\ College of Education, University of South Africa, South Africa
}

\begin{abstract}
Problem statement: In recent years, much has been written about constructivist learning theories and their applications to outcomes-based teaching and learning environments in South Africa. Approach: Little, if any, has been said about the implications of these ideas and practices for teacher professional development and teacher education. The introduction of the National Curriculum Statement (NCS) Policy requires teachers to acquire new skills, knowledge, attitudes and values and to employ a wide variety of teaching strategies, in order to enable students to construct their own knowledge. Results: The purpose of this desktop review is to rethink teacher professional development within a constructivist framework. Conclusion: In this article, we argue that teacher professional development can fit the context and, more specifically, in outcomes-based settings, as well as proposed a move away from a mechanistic world-view (modernist and behaviorist approach) to a holistic world-view (constructivist and situational or contextual approach) of teacher professional development.
\end{abstract}

Key words: National Curriculum Statement (NCS), learning environments, professional development, rapidly evolving, societal needs, surface features

\section{INTRODUCTION}

In recent years, an array of research has been conducted on the subject of teacher professional development. Teacher Professional development plays an important role in changing teachers' teaching methods and assisting teachers to move beyond a comprehension of the surface features of a new idea or innovation, to a deeper understanding of a topic. Professional development provides teachers with opportunities to explore new roles, develop new instructional techniques, refine their practice and broaden themselves, both as educators and as individuals (Komba and Nkumbi, 2008). For Zakaria and Daud (2009), good teachers constitute the foundation of good schools and improving teachers' skills and knowledge is one of the most important investments of time and money that local, state and national leaders can make in education.

In the traditional and the scientific paradigm of teacher professional development, teachers are often perceived as bureaucrats, implementing a carefully specified curriculum and instructional procedures to produce standard products, referred to as students. This paradigm is compatible with the behavioristic view of learning, in which both curriculum and instruction are broken down into small, sequential steps dictated by the teacher. The introduction of the National Curriculum Statement (NCS) Policy embodies a significant number of challenges. Among others, it requires the acquisition of new skills, knowledge, attitudes and values; and it requires teachers to employ a wide variety of teaching strategies, in order to enable students to construct their own knowledge. The purpose of this desktop review is to rethink teacher Professional development within a constructivist framework. Hence, teacher professional development should shift from a behavioristic towards constructivist approach.

In recent years, much has been written about constructivist learning theories and their application to outcomes-based teaching and learning environments in South Africa. Little, if any, has been said about the implications of these ideas and practices for teacher professional development and teacher education. In this article we argue that teacher professional development programs should be underpinned and guided by principles that are compatible with the emerging paradigm. Drawing from critical pedagogy and social constructivism, this article is organized into four sections. The first section investigates emerging trends and challenges in teacher professional development. The second section explores characteristic features of the constructivist professional development. The third section reports on the models of professional

Corresponding Author: Pitsoe, V.J., Department of Educational Studies, College of Education, University of South Africa, South Africa 


\section{J. Social Sci., 8 (3): 318-324, 2012}

development that is consistent with the emerging paradigm. The final section proposes a shift towards a constructivist professional development approach.

Emerging trends and challenges in teacher professional development: There is a considerable volume of research on the emerging trends in teacher professional development. Since the mid-80s, education systems have sought to respond to rapidly evolving societal needs. In this process, the teaching profession, as a key mediating agency between society and the young generation, has come under considerable pressure; and teacher training, which is a key area of policy intervention, has been in a state of flux worldwide (Delannoy, 2000). Such re-thinking came in response to new expectations from the macro level, the school and the profession. Delannoy (2000) notes that the trends varied in nature and intensity from one region to the next and they impacted on education systems that were vastly different in the first place. Some poised to reinvent education, while others were still struggling with the basics of access; some were coming from a centralized tradition and others from a decentralized tradition.

Experience around the world in developing, industrialized and information-based countries suggests that professional development is the key determining factor towards improved student performance (Zakaria and Daud, 2009). In this article, professional development is considered to be a critical component in the implementation of the NCS Policy. Effective professional development experiences are designed to assist teachers in developing a new understanding of teaching and learning (Zakaria and Daud, 2009). To be effective, professional development must provide teachers with a way to apply that which they have learnt directly to their teaching (Zakaria and Daud, 2009). The research found (Holland, 2005) that teachers were more likely to change their instructional practices and gain greater subject knowledge and improved teaching skills when their professional development was directly linked to their daily experiences, as well as aligned with standards and assessments.

Current research (Kriek and Grayson, 2009) into the effective professional development of teachers indicates that this is nothing new but, in recent years, the way in which it has been structured and delivered, has been reconceptualised. Charner-Laird (2007) notes that many scholars still assert the need for new approaches to professional learning that are responsive to the needs of both schools and teachers. Such approaches may take various forms, such as for example, cognitive coaching. The idea of cognitive coaching is based on the idea of the construction of knowledge rather than the transfer of knowledge. Adult learning principles give major support to cognitive coaching and predict its success. These approaches to curriculum development and teacher professional development had repeatedly proven to be ineffective. Kriek and Grayson (2009) highlight the fact that traditional "one-shot" approaches to professional development are inadequate and inappropriate in the context of current educational reform efforts. In addition, they are also out of step with current research into teacher learning. These studies also indicated that the professional development of teachers is "intellectually superficial, disconnected from deep issues of curriculum and learning, fragmented and noncumulative". Although it is widely acknowledged that changes are needed, only limited information is available about the factors that contribute to effective professional development in mathematics and science, as are examples of programmes that result in effective practices (Kriek and Grayson, 2009).

Professional development is not a static concept. It is a social construct and fluid in nature. Today, professional development also includes providing occasions for teachers to reflect critically on their practices and to fashion new knowledge and beliefs about content, pedagogy and learners (DarlingHammond and McLaughlin, 1995). In the emerging paradigm, constructivist professional development adopts a bottom-up approach. Darling-Hammond and McLaughlin (1995) assert that, starting with pre-service education and continuing it throughout a teacher's career, teacher development must focus on deepening teachers' understanding of the processes of teaching and learning, as well as of the students they teach. In addition, effective professional development involves teachers both as learners and as teachers and allows them to struggle with the uncertainties that accompany each role. It furthermore displays a number of characteristics:

- It must engage teachers in concrete tasks of teaching, assessment, observation and reflection, which will illuminate the processes of learning and development

- It must be grounded in inquiry, reflection and experimentation that are participant-driven

- It must be collaborative, involving a sharing of knowledge among educators and a focus on teachers' communities of practice, rather than on individual teachers

- It must be connected to and derived from teachers' work with their students 


\section{J. Social Sci., 8 (3): 318-324, 2012}

- It must be sustained, ongoing, intensive and supported by modelling, coaching and the collective solving of specific problems pertaining to practice; and

- It must be connected to other aspects of school change (Darling-Hammond and McLaughlin, 1995)

In the light of the above, professional development is a lifelong learning activity. Given the speed of societal change and knowledge accumulation, policymakers and practitioners have come to realize that there is no way that even a good initial education program could equip a teacher with all the knowledge, skills and values required for a teaching career (Delannoy, 2000). This is especially the case when one considers that teachers develop different needs as their careers advance-from survival to instructional skills at basic, mature and expert levels. This has resulted in a shift away from a fragmented vision of discrete "pre" and "in" -service training to one of teacher development as a continuum along "the three Is," namely teacher "initial education," "induction" (structured support upon entry into the profession) and "in-service continuous professional development" (Delannoy, 2000). In addition, this continuum is characterized by interaction between inductees and experienced mentors, as well as by feedback on in-service to initial education programs.

Characteristic features of constructivist professional development: In the scientific paradigm, teacher professional development activities have adopted a positivist approach. At a philosophical level, among others, teacher professional development is influenced and guided by traditional or positivist principles; and behaviorist and Objectivist traditions. It is also underpinned by the idea of cascading that was widely used and which is based on the idea of the transfer of knowledge rather than the construction of knowledge. Therefore, it flows from the theoretical frameworks of a mechanistic world-view (bureaucracy, Taylorism, Fordism, behaviourism, objectivity, process-based, linear, compartmentalised and step-by-step-a clock metaphor). In practice, the activities are largely dominated and characterised by a top-down approach. Within an organisational perspective, it could be inferred that traditional teacher professional development is hierarchical, with all the power centralised in the policymakers or bureaucrats as the carriers of the knowledge that needs to be transferred to teachers; and as the initiators, organisers and managers of the learning that must take place, while teachers are the recipients of knowledge to be absorbed.
In contrast, the holistic world-view operates in a reverse direction. Professional development is a situational variable. With reference to its characteristic features and the view of knowledge, constructivist professional development appears to be compatible with the beliefs and assumptions of the emerging world-view. Therefore, constructivist professional development can be typified as fitting through the lens of the emergent paradigm. The concept of professional development is guided and influenced by the contingency viewpoint and it rejects the notion that a particular viewpoint constitutes a "one-size-fits-all" approach. Given that reality is seen to be created via processes of social exchange and is historically situated, social constructivists are interested in the collective generation of meaning among people. Therefore, the characteristic feature with a view to knowledge is relational, tentative and largely perceptual.

Constructivist professional development has holistic and artistic features. According to Black (1999), the holistic world-view takes its distinctive features from the dimensions of any artistic event. Central to the emergent paradigm is the distinctive feature of contextuality. Maykut and Morehouse (1994) emphasise that qualitative research values context sensitivity, which understands a phenomenon in all its complexity and within a particular situation and environment. Hence, the view of phenomena is complex, holistic and a product of empirical processes. In essence, professional development in a constructivist setting is based upon a situational viewpoint. Therefore, constructivist professional development may be typified as fluid, systemic, integrative orders and largely heterarchical in nature.

Constructivist professional development has the metaphorical descriptive features of a holon. The holon provides the basis for a new principle in the holistic world-view, namely that the whole is always greater than the sum of its parts and, paradoxically, the whole is contained in each part while no whole is complete in itself (Black, 1999). Furthermore, wholeness is the primary reality according to the holistic world-view. Within the holistic metaphor, the leader is not simply the manager who is responsible for increased efficiency, productivity and profit, but rather an artist (Black, 1999). The leader as an artist is more concerned with insight, symbolism, intuition and stories than with economic performance. For Bremmer (Black, 1999), the leader is not simply a manager who is responsible for increased efficiency, products and profit, but rather a key artist. The role of the leader as an artist, according to Bremmer (as cited by Black, 1999), is equivalent to that of the conceptual artist who utilises extensive 
communication systems in the creation of the work, so that extremely complex signs, symbols, images, text and various forms of media are designed to include the viewer-consumer in sharing or completing, or consuming complex codes of meaning or services.

In contrast, in the emerging paradigm, it is characterised by mutual causation with multi-causal factors and explained by deductive, inductive and integrative reasoning. In this school of thought, leadership is situational. Wheatly (Black, 1999) posits that leadership is always dependent upon the context, but the context is established by relationships. Professional development in the emergent paradigm recognises the ecological connections that exist in the post-modern world. As a process or relationship, it demands a new understanding of power. This power is underpinned by the principle of subsidiarity. Handy (Black, 1999) defines subsidiarity as the reverse of empowerment, as the principle whereby the higher order body does not take into account itself as the responsibilities which properly belong to a lower order body.

In the scientific paradigm, professional development has its focus on the achievement of organisational goals; and insists on an orientation towards the transformation of consciousness and social change. In contrast, professional development in the emergent paradigm focuses on both social and global transformation (Black, 1999). The emergent paradigm sees professional development's ultimate aim/goal as the refinement and the achievement of a human community. Therefore, the view of change/orientation of the future is indeterminate, unpredictable and morphogenetic.

Models of professional development that is consistent with the emerging paradigm: There are multiples of models of teacher professional development. However, this study will draw heavily from Sparks and Loucks-Horsley (1989) works. Research (Sparks and Loucks-Horsley, 1989) indicates that, in the early 1970s, a growing concern about the effectiveness of in-service education resulted in a spate of studies to determine the attitudes of educators about these programmes. The findings indicated almost unanimous dissatisfaction with current efforts, but showed a strong consensus that in-service education was critical if school programmes and practices were to be improved. During the late 1970s and early 1980s, several major studies and reviews contributed to the understanding of the characteristics of effective staff development, focusing not on attitudes, but on actual practices.

The resulting list of effective practices, which is well known by now, included, among others, programmes conducted in school settings and linked to "school-wide" efforts, with teachers participating as helpers to each other and, together with school principals, as planners of in-service activities. Staff development came of age in the 1980s. It was the focus of countless conferences, workshops, articles, books and research reports. State legislators and administrators of local school districts saw staff development as a key aspect of school improvement efforts. Many school districts initiated extensive staff development projects to improve student learning. Research on these projects and craft knowledge, generated by staff developers, substantially advanced the understanding of effective staff development practices, beyond the overview studies of the early 1980s referred to above.

The five models of professional development, as developed by Sparks and Loucks-Horsley (1989), constitute a framework that ensures variety in professional development, while it also links model purposes(s) with particular professional and personal learning goals.

Individually guided development: The teacher designs his or her learning activities. An assumption of this model is that individuals are motivated by being able to select their own learning goals and means for accomplishing those goals. A belief that underlies this model is that self-directed development empowers teachers to address their own problems and, by so doing, creates a sense of professionalism.

Observation and assessment: Instructional practices are improved if a colleague or other person observes a teacher's classroom practice and provides feedback. Having someone else in the classroom to view instruction and provide feedback or reflection, is also a powerful way of impacting upon classroom behaviour. The person observing acts as another set of "eyes and ears" for the teacher. Observers also learn as they view their colleagues in action.

Involvement in a development or improvement process: Systemic school improvement processes typically involve assessing current practices and determining a problem of which the solution would improve student outcomes. The solution might include developing curricula, designing programmes or changing classroom practices. New skills or knowledge may be required and can be attained through reading, discussion, observation, training and experimentation. Consequently, involvement in the improvement process can result in many new skills, attitudes and ways of behaviour. 


\section{J. Social Sci., 8 (3): 318-324, 2012}

Training: A training design includes an expert presenter who selects the objectives, learning activities and outcomes. Usually the outcomes involve awareness, knowledge or skills development, but changes in attitude, the transfer of training skills and "executive control" need to be addressed as well. The improvement in teachers' thinking should be a critical outcome of any training programme. The most effective training programmes include the exploration of theory, demonstrations of practice, supervised trials of new skills with feedback on performance and coaching within the workplace.

Inquiry: Teachers formulate questions about their own practices and pursue answers to those questions. Inquiry involves the identification of a problem, data collection (from the literature and classroom data), data analysis and changes in practice, followed by the collection of additional data. The inquiry can be done individually or in small groups. This model is built on the belief that the mark of a professional teacher is the ability to take "reflective action."

Towards a holistic/constructivist professional development approach: The quality of education in South Africa has been an issue of much debate. This article argues that quality of education is tied to holistic teacher professional development. Holistic development of teachers focuses on four levels, namely the environment, the "self", content knowledge and pedagogical content knowledge. Delannoy (2000) asserts that the future teacher must be exposed to all the theoretical, practical and ethical dimensions of his/her practice. Furthermore, the content of the training must be based on an analysis of the job description and its delivery mode. The teacher is engaged in a collective project that requires social and negotiating skills. Professional development efforts are no longer limited to teachers, or embracing entire districts, but are increasingly targeted at schools in their entirety, thus making it possible to combine the generic with contextspecific skills (Delannoy, 2000). Improvement strategies, instead of piecemeal offerings, are driven by clear, coherent plans, bridging broader strategic goals with locally perceived needs. Residential training has been giving way to on-the-job problem-solving. In lieu of "experts" transmitting skills to passive audiences, the teachers themselves are studying classroom processes and the trainers of yore are also providing advisory, planning and facilitating services (Delannoy, 2000).

In the South African context, Kriek and Grayson (2009) proposed that teachers require simultaneous development along three dimensions, namely content knowledge, teaching approaches and professional attitudes. The HPD Model was designed to facilitate such development. Using the design framework of Gerber et al. (2011) Stiles for the professional development of mathematics and science education, a model with several important features was developed (Kriek and Grayson, 2009). There is a dire need to equip South African teachers with a significant number of skills, such as classroom management and leadership, policy implementation, curriculum issues, inter-relationships with the organisation and quality assurance among others, in order to cope with the daily challenges faced in outcomes-based classrooms. From an organisational perspective, every school is a unique entity and teachers needs differ from one school to the next. For example, the training needs of farm school teachers and semi-urban/urban teachers differ significantly. Teachers should be developed in accordance with their contexts. Thus, for effective professional development to take place in South African schools, the specific needs of teachers should determine and guide such training. This research argues that successful professional development is designed in accordance with teacher-identified needs at a specific school level and not with a "one-size-fitall" approach in mind.

From a policy perspective, education policy, aimed at educational change, only becomes reality once it has been implemented at the micro (classroom) level. Smith (2001) notes that teachers are indeed the key roleplayers in this implementation phase and they are, unfortunately more often than not, the silent voices in this process, ignored and discounted at this stage of educational change (Smith, 2001). How they experience and understand the policy change, or how the human side of policy change is contextualised, remains a mystery to be explored and explained (Smith, 2001). Notwithstanding the growing amount of literature on educational change and policy change, relatively little has been done with regard to the experiences of teachers and policy change in the context of developing countries, such as South Africa.

Central to this article is the assumption that professional development is a fluid concept and that it should be contextualised. During the past two decades, several approaches moved from a rationalist point of view to a social constructivist perspective by integrating social interaction. Although the outlines of a new paradigm for professional development policy are emerging, the hard work of developing concrete exemplars of the policies and practices that model "topdown support for bottom-up reform" has only just begun (Darling-Hammond and McLaughlin, 1995). Furthermore, 
the changed curriculum and pedagogy of professional development will require new policies that foster new structures and institutional arrangements for teachers' learning. At the same time, there is need to undertake a strategic assessment of existing policies to determine to what degree they are compatible with the vision of learning as constructed by teachers and students, as well as with a vision of professional development as a lifelong, inquiry-based and collegial activity.

Darling-Hammond and McLaughlin (1995) claim that new approaches are needed for the professional education of teachers and that they require new structures and support systems. New initiatives cannot promote meaningful or long-term change in teachers' practices by themselves, if they are embedded in a policy structure that is at odds with the vision of student and teacher learning that reforms seek to bring alive (Darling-Hammond and McLaughlin, 1995). In other words, new wine and old wine needs new bottles, or else incentives and support structures for teacher development will be counter-productive or nonexistent. Many of the modernist assumptions on which traditional professional development is based, no longer hold water in our present-day world and this has resulted in philosophers questioning modern issues, using a different paradigm. This situation requires that professional development, in a constructivist setting, be approached from a holistic or situational approach perspective. Thus, a new set of principles is apposite.

Professional teacher development belongs to the scientific and the emerging world-views. In a modernist framework, the nature of knowledge is universal, objective and fixed (independent of the person with knowledge) and is grounded in the theoretical tradition of behaviourism. At a philosophical level, traditional professional development is, among others, influenced and guided by positivist, objectivistic/modernistic and/or behaviouristic principles. In this tradition, authority is hierarchically transmitted. Furthermore, the patriarchal and hierarchical social pattern is maintained by systems of command and control at all levels of the hierarchy.

Most of the studies conducted in the emergent paradigm on professional development have a significant number characteristic features. Among others, these studies largely depart from a basis of qualitative and interpretivist frameworks. In addition, these studies emphasise situational variables, while rejecting the notion of a particular viewpoint (e.g., a traditional or behavioural or systems viewpoint) as a one-size-fits-all professional development approach. They are furthermore characterised by holistic and artistic features, discrete units, hierarchical orders, mutual causation with multi-causal factors and explained by deductive, inductive and integrative reasoning. The main findings of the study are that:

- The characteristic features of the traditional professional development are compatible with the scientific paradigm

- constructivist/holistic professional development is influenced and guided by contingency theories

- Teachers' beliefs are deemed important in professional development

- Teachers' personal practical knowledge exerts a major influence on the way in which teachers respond to educational change

- Successful teacher professional development fits the context; and

- That the top-down approach to teacher professional development is not compatible with the emerging paradigm

The emerging paradigm has noteworthy implications for social researchers, teachers, principals and policymakers. There is a need to open a dialogue on the concept of constructivist/holistic professional development, in its broadest sense, for the purpose of acquiring theoretical (philosophical) and practical understanding, influenced and guided by research. For the purposes of effective training and implementing outcomes-based curriculum policy, this article proposes that a future teacher professional development policy and, more specifically, in education management and leadership, policy implementation, curriculum issues, inter-relationships with the organisation and quality assurance, aimed at the South African education system, should:

- Influenced and guided by contingency theories

- Underpinned by Kriek and Grayson (2009) HPD Model

- Contextualised and adopting a bottom-up approach

- Consider teachers' beliefs and experiences as the starting point of professional development

- Integrated with district goals and guided by a coherent long-term plan

- Driven by disaggregated data on student outcomes and designed in accordance with teacher-identified needs

- Primarily school-based

\section{CONCLUSION}

The emergent paradigm appears to have a significant number of implications for professional 
development and, more specifically, with regard to skills, such as classroom management and leadership, policy implementation, curriculum issues, interrelationships with the organisation and quality assurance in outcomes-based classrooms, among others. It, inter alia, also calls for a dramatic shift in professional development focus, away from the transmission model of teaching towards one that is much more complex, situational/contextual and interactive. In the emergent paradigm, professional development is organimistic, morphogenesic, systemic and holistic in nature.

\section{REFERENCES}

Black, P.M., 1999. 'The new is elsewhere': Women's leadership in community-profit organisations. Published Doctoral Thesis, Queensland University of Technology.

Charner-Laird, M., 2007. Ready and Willing: SecondStage Teachers and Professional Collaboration. 1st Edn., Harvard Graduate School of Education, pp: 88.

Darling-Hammond, L. and M.W. McLaughlin, 1995. Policies that support professional development in an era of reform. Phi Delta Kappan, 76: 597-604.

Delannoy, F., 2000. Teacher Training or Lifelong Professional Development? World-wide Trends and Challenges. Knowledge Enterprise, Inc.
Gerber, B.L., E.A. Marek and E.P. Martin, 2011. Designing research-based professional developmyent for elementary school science and mathematics. Educ. Res. Int., 2011: 8-8. DOI: $10.1155 / 2011 / 908014$

Holland, H., 2005. Teaching teachers: Professional development to improve student achievement. Am. Educ. Res. Assoc., 3: 1-4.

Komba, W.L. and E. Nkumbi, 2008. Teacher professional development in tanzania: Perceptions and Practices. J. Int. Cooperat. Educ., 11: 67-83.

Kriek, J. and D. Grayson, 2009. A holistic professional development model for South African physical science teachers. South African J. Educ., 29: 185-203.

Maykut, P. and R. Morehouse, 1994. Beginning Qualitative Research: A Philosophic and Practical Guide. 1st Edn., Routledge, ISBN: 0750702737, pp: 194.

Smith, B., 2001. Primary school teachers' experiences of education policy change in South Africa. Doctoral Thesis, University of Pretoria, South Africa.

Sparks, D and S. Loucks-Horsley, 1989. Five models of staff development for tearchers. J. Staff Dev., Fall, 10: 40-57.

Zakaria, E. and M.Y. Daud, 2009. Assesing mathematics teachers' professional development needs. Eur. J. Soc. Sci., 8: 225-231. 